\title{
Management of the no-reflow phenomenon
}

\author{
Eduard Margetić* \\ University Hospital Center Zagreb, Zagreb, Croatia
}

Primary percutaneous coronary intervention $(\mathrm{PPCl})$ is the preferred reperfusion strategy for treating acute ST-segment elevation myocardial infarction (STEMI). The main goals are to restore epicardial infarct-related artery (IRA) patency and achieve microvascular reperfusion as early as possible, thus limiting the extent of irreversibly injured myocardium. Unfortunately, in many patients myocardial perfusion remains poor despite the successful restoration of IRA patency. The lack of adequate myocardial perfusion of a given coronary segment after prolonged ischemia without angiographic evidence of mechanical vessel obstruction is termed. It is clinically important as it is independently associated with increased occurrence of malignant arrhythmias, heart failure, in-hospital and long-term mortality. After the onset of STEMI an efficient emergency system that reduces ischaemic time is crucial for no-reflow prevention in patients undergoing $\mathrm{PPCl}$. The risk of distal embolization is related to thrombus burden, which may be reduced by the use of glycoprotein Ilb/Illa inhibitors. The most potent endogenous mechanism to limit infarction is ischaemic preconditioning. Among patients undergoing PPCI thrombus aspiration has an emerging role. Other pharmacological agents (calcium channel blockers, sodium nitroprusside, adenosine, nicorandil) show promise for reduction of no reflow but require validation in larger, randomized trials.

In conclusion, to improve clinical outcomes of STEMI we need to focus on increasing microvascular flow to ischaemic (but not infarcted) myocardium and reducing ischaemiareperfusion injury. No reflow is a multifactorial process, so it is unlikely that one treatment will prevent or cure the process. Thus, prophylactic vasodilator therapy, mechanical devices, ischaemic preconditioning and potent platelet inhibitors in combination are more likely to be effective than any of these alone.

KEYWORDS: no-reflow, myocardial infarction, primary percutaneous coronary intervention.

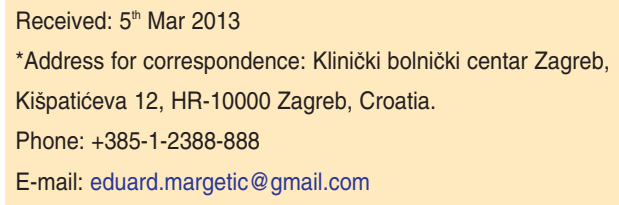

\section{Literature}

1. Eeckhout E, Kern MJ. The coronary no-reflow phenomenon: a review of mechanisms and therapies. Eur Heart J. 2001;22(9):729-39.

2. Galiuto, L. Optimal therapeutic strategies in the setting of post-infarct no reflow: the acute myocardial infarction. J Am Coll Cardiol. 1998;32(4):898-903.

3. Rezkalla SH, Kloner RA. Coronary no-reflow phenomenon: from the experimental laboratory to the cardiac catheterization laboratory. Catheter Cardiovasc Interv. 2008;72:9507.

4. Yellon DM, Hausenloy DJ. Myocardial reperfusion injury. N Engl J Med. 2007;357:1121-35.

5. Niccoli G, Burzotta F, Galiuto L, Crea F. Myocardial no-reflow in humans. J Am Coll Cardiol. 2009;54:281-92. 